\title{
Editorial
}

Pensar en Movimiento:

Revista de Ciencias del Ejercicio y la Salud

EISSN 1659-4436

Vol. 11, No.2, pp. 1- 2

\section{AUTORÍA, ORIGINALIDAD Y TRANSPARENCIA}

Conforme Pensar en Movimiento crece y se consolida, las personas que estamos a cargo hemos venido adquiriendo conciencia de la necesidad de informar mejor sobre las políticas y tendencias editoriales a nivel internacional. Por ejemplo, a partir de este número, nuestra revista advierte que está tomando acciones concretas para detectar y prevenir el plagio. También estamos siendo cuidadosos con los procedimientos de revisión, aceptación, diagramación y publicación de manuscritos, en un intento por dar información original y veraz. Nos complace además ver que muchas revistas están adoptando una política que ha estado vigente por varios años en nuestra revista: la publicación electrónica inmediata de cada artículo aceptado, sin esperar a completar el número correspondiente.

El quehacer científico es cada vez más una labor de equipo, por lo tanto: en cada manuscrito publicado han participado múltiples colaboradores en distintas calidades, desde los investigadores hasta el personal de apoyo administrativo, técnicos, asistentes y sujetos experimentales. Sin embargo, tanto el prestigio como la responsabilidad de la autoría deberían corresponder solamente a aquellos pocos que han hecho aportes considerables en varias etapas del trabajo. En Pensar en Movimiento tenemos como política pedir que todos los manuscritos con dos o más autores declaren formalmente la participación de cada uno en las etapas de financiamiento, diseño del estudio, recolección de datos, análisis estadístico e interpretación de resultados, y preparación del manuscrito. Todo coautor debería haber participado de lleno, como mínimo, en tres de ellas. Inclusive, cualquiera de los coautores debería estar en capacidad de presentar el trabajo ante un auditorio y responder satisfactoriamente las preguntas. Los demás colaboradores pueden ser mencionados en los agradecimientos, siempre y cuando se les pida su autorización para ello.

Los manuscritos que se envían a Pensar en Movimiento deben ser originales e inéditos. Esto significa que los autores deben dar fe de que el trabajo enviado a revisión no ha sido publicado anteriormente en ningún otro medio ni en otros idiomas (además de no estar en proceso de revisión simultánea en otra revista); la excepción a esta norma son las contribuciones a nuestra sección Costa Rica sin Fronteras, cuyo objetivo es 
precisamente divulgar los trabajos publicados por investigadoras e investigadores costarricenses en otros idiomas, mediante la publicación de los resúmenes en español con referencia a la publicación original. Es importante, además, señalar que la colocación de preprints (manuscritos en borrador) en un repositorio institucional o personal sí es permitida por nuestra revista, pues dicho material (que aún no ha sido revisado por pares académicos, ni ha sido editado y diagramado) se considera un medio para divulgar la información oportunamente antes de su publicación. Una vez publicado en PENSAR EN MOVIMIENTo, cada manuscrito está disponible en acceso abierto y altamente visible para toda la comunidad internacional.

Otra tendencia que se ha visto beneficiada por la publicación electrónica de revistas consiste en poner a disposición de los lectores las bases de datos originales en forma de archivos complementarios. Esta práctica es totalmente voluntaria, pero tiene la ventaja de promover la transparencia, al permitir a los lectores hacer sus propios análisis, confirmar resultados y obtener información útil para metaanálisis que no siempre está disponible en el manuscrito principal. Es aceptable también colocar otros archivos que pueden complementar la información del manuscrito, como fotografías, videos, descripciones del estudio en lenguaje común, etc.; los autores deben respetar los derechos de propiedad intelectual y de imagen asociados con estos materiales.

Gracias por confiar en nuestra revista como fuente de información y medio de divulgación para su trabajo científico.

Luis Fernando Aragón V., Ph.D., FACSM

Director, Pensar en Movimiento Universidad de Costa Rica

\author{
(c) 1 (1) 9 \\ Esta obra está bajo una \\ licenciaCreativeCommons Atribución-NoComercial-SinDerivadas 3.0 Costa Rica.
}

